\title{
REVIEW OF SOCIO DEMOGRAPHIC FACTORS AND OBSTETRIC CAUSES OF STILLBIRTHS AT TERTIARY CARE HOSPITAL
}

\author{
Bangal Vidyadhar B, Chandaliya Rajiv M, Pandit Hrishikesh A \\ Department of Obstetrics and Gynecology, Rural Medical college, Loni, Ahmednagar, MS
}

\begin{abstract}
Background: - Occurrence of stillbirth pose difficult situation for the obstetrician and cause great psychological and emotional trauma to the couple and the family. It reflects the suboptimum quality of maternal and child health services. Stillbirth rates are unacceptably high in developing countries. Study was carried out to find out the causes of stillbirths and the socio demographic profile of women , who had stillbirth. Material and Methods: - A clinical observational study was undertaken at tertiary care teaching hospital over a period of 10 months from January 2011 to October 2011. Results:Illiteracy, rural residence, lack of antenatal care ,low socioeconomic status were commonly associated with stillbirths. Pregnancy induced hypertension, ante partum hemorrhage ,cord related accidents and preterm labour were mainly responsible for stillbirths .Low birth weight and extreme prematurity were directly related to stillbirths. Conclusion:- High rate of ante partum stillbirths due to hypertension, ante partum hemorrhage and preterm labour can be reduced by early recognition of the problem ,regular antenatal check ,color Doppler study to diagnose fetal growth restriction, and timely obstetric intervention .Ultrasonograpy to diagnose cord abnormalities ,use of intrapartum electronic fetal monitoring, partograph and prevention of prolongation of second stage of labour will help in reduction of stillbirths.
\end{abstract}

Keywords:- Perinatal mortality ,Perinatal deaths, Stillbirths

\section{INTRODUCTION}

Occurrence of stillbirth is a tragic event faced by the obstetrician .It has many implications for the couple, family and the health care provider. It reflects a failure or lapse in implementation of maternal and child health care programme .It is estimated that approximately 3.2 million stillbirths occur in the world every year. Majority of them take place in underdeveloped and developing countries [1].Stillbirths contribute to more than half of the perinatal deaths .More than two third of the stillbirths take place during pregnancy and remaining during course of labour.[2,3]Suboptimum care during pregnancy and labour results in macerated stillbirths and fresh stillbirths respectively.[4,5]Stillbirths during pregnancy are usually due to lack of adequate nutrition ,hypertensive disorders ante partum hemorrhage, genetic abnormalities in fetus, maternal infections and exposure to some toxic agents .[6]Intrapartum deaths are usually related to prolong and neglected labour ,malpresentations and cord related complications. Present study was carried out to find out the socio economic profile of women who had stillbirths after institutional delivery and different medical and obstetric causes related to these stillbirths. Preventive measures are suggested in the end to reduce the perinatal mortality as a result of stillbirths.

\section{MATERIAL AND METHODS}

The present study was a hospital based retrospective observational study carried out at Pravara rural hospital, which is a tertiary care teaching hospital in Ahmednagar district of Maharashtra .All pregnant women who after admission, delivered a stillborn baby during a period of one year from January 2011 to December 2011 were included for analysis in the study .The data regarding socio demographic profile and antenatal investigations to find out cause of stillbirths was collected from the indoor case sheet. The information regarding intrapartum events was collected from labour record and partograph of every case .The data related to total deliveries and stillbirths was collected from medical record section of Pravara Rural Hospital. Relevant data was entered on a structured performa and then transferred to master chart .The statistical analysis was performed using $\mathrm{Z}$ test. Variations of $\mathrm{P}<0.05$ were considered to be statistically significant. 
IOSR Journal of Pharmacy

Vol. 2, Issue 3, May-June, 2012, pp.475-478

\section{RESULTS}

During the study period, the total number of deliveries were 3997 and there were 131 stillbirths .The stillbirth rate was 33.30 per thousand births (Table 1).Sixty one percent stillbirths occurred during antepartum period and remaining 39 percent during intrapartum period .Perinatal mortality rate was 51 per thousand births .Out of 131 stillbirths, 14 percent were among teenage primigravidas and 3 percent were among elderly primigravidas .Majority of women were in their third decade of life .Women from rural residential area and from lower socio economic class had more stillbirths as compared to their counterparts .Primigravida women delivered more stillborn babies than multigravidas(Table 2) .It was observed that pregnancy induced hypertension and preterm labour resulting in birth of preterm babies were the common obstetric problems related to causation of stillbirths .Other causes being cord related accidents like cord prolapse ,true knot formation of cord entanglement ,either nuchal or around fetal body parts. Malpresentations, prolonged and obstructed labour and labour abnormalities resulted in many fresh stillbirths. Antepartum hemorrhage,especially accidental hemorrhage resulted in acute placental insufficiency and fetal deaths. Fetal congenital abnormalties and postdated pregnancy was responcible for many macerated stillbirths.(Table 3) It was observed that eighty eight percent of stillborn babies were low birth weight ,of which sixty six percent were very low birth weight .Seventy eight percent of stillborn babies were premature of which seventy five percent had gestational age of below 34 weeks.

Table no. 1 perinatal outcome

\begin{tabular}{|c|l|c|}
\hline $\begin{array}{c}\text { Sr. } \\
\text { No }\end{array}$ & Indicator & Number \\
\hline 1 & Total births & 3997 \\
\hline 2 & Total live births & 3794 \\
\hline 3 & Perinatal deaths & 203 \\
& & 131 \\
& - Stillbirths & 072 \\
& - Neonatal deaths & \\
& & $50.78 / 1000$ births \\
\hline 4 & Perinatal mortality rate & $33.30 / 1000$ births \\
\hline 5 & Stillbirth rate & \\
\hline
\end{tabular}

Table .2 Socio demographic profile of women with stillbirths

\begin{tabular}{|l|l|c|c|}
\hline $\begin{array}{c}\text { Sr. } \\
\text { No }\end{array}$ & Socio demographic parameter & $\begin{array}{c}\text { No. of cases } \\
(\mathbf{n = 1 3 1})\end{array}$ & $\begin{array}{c}\text { Percentag } \\
\text { e }\end{array}$ \\
\hline 1 & Age distribution & 18 & \\
& -Below 20 years & 109 & 14 \\
& -20-30 years & 04 & 03 \\
& -Above 30 years & & \\
\hline 2 & Parity distribution & 73 & 56 \\
& -Primigravida & 58 & 44 \\
\hline 3 & -Multigravida & & \\
& Socio economic class & & \\
& & 03 & 2.29 \\
& -(I) & 05 & 3.81 \\
& -(II) & 37 & 28.24 \\
& -(III) & 52 & 39.69 \\
& -(IV) & 34 & 25.95 \\
& & & \\
\hline 4 & Unbooked/Booked & $102 / 29$ & $78 / 22$ \\
\hline 5 & Area of residence-Urban/Rural & $10 / 121$ & $08 / 92$ \\
\hline 6 & Marital status & $0 / 131$ & $-0 / 100$ \\
& (unmarried/married) & & \\
\hline
\end{tabular}


IOSR Journal of Pharmacy

Vol. 2, Issue 3, May-June, 2012, pp.475-478

Table. 3 Distribution of stillbirths as per the etiology

\begin{tabular}{|c|l|c|c|}
\hline $\begin{array}{c}\text { Sr. } \\
\text { No }\end{array}$ & Etiology of Stillbirth & $\begin{array}{c}\text { No. of cases } \\
(\mathbf{n = 1 3 1})\end{array}$ & Percentage \\
\hline 1 & Pregnancy induced hypertension & 33 & 25.19 \\
\hline 2 & Prematurity & 31 & 23.66 \\
\hline 3 & Antepartum haemorrhage & 16 & 12.21 \\
\hline 4 & Cord accidents & 09 & 07.63 \\
\hline 5 & Fetal malformations & 06 & 06.87 \\
\hline 6 & Postdatism & 08 & 06.10 \\
\hline 7 & Malpresentations & 06 & 04.58 \\
\hline 8 & Labour abnormalities & 05 & 03.81 \\
\hline 9 & $\begin{array}{l}\text { Medical disorders } \\
\text { (Anemia,Heart disease,Liver } \\
\text { disease) }\end{array}$ & & 03.81 \\
\hline 10 & Idiopathic & 08 & 06.10 \\
\hline
\end{tabular}

\section{DISCUSSION}

Stillbirths contribute to majority of perinatal deaths .Sometimes they occur suddenly and unexpectedly and at times they are anticipated by the obstetrician. Irrespective of type time of occurrence and cause ,they cause lots of psychological trauma to the patient and relatives. With the news of the stillbirth , the dream of fulfillment of motherhood disappears and is gets replaced by state of shock the severity of this problem is much more with sudden intrapartum deaths due to birth asphyxia due to various reasons.In the present study, the rate of stillbirths(33.30 per 1000 births) was comparable to the rates reported by other authors.[7,8,9,10,11] and was much less than reported by few authors.[12,13]The stillbirths were common during antepartum period $(61 \%)$ than during intrapartum period( $39 \%$ ).Common causes of antepartum stillbirths were placental insufficiency secondary to hypertension an antepartum hemorrhage.Similar observations were reported by Ravikumar,Nayak and Dalal and Uchil.[11,7,14]Congenital malformation of fetus were responsible for 7 percent of stillbirths.Ravikumar et al and korde et al reported slightly higher rates of malformations causing stillbirths.[11,8]Among all the socio demographic factors studied, lack of antenatal care,lower socio economic class and illiteracy were found to be significantly associated with higher still birth rates.(p value less than 0.05) Kameshwaran and Ravikumar et al and Chitrakumari have reported similar observations in their studies.[9,11,13] Prematurity and low birth weight due to various medical or obstetrical causes were associated with more than eighty percent of stillbirths. Maternal under nutrition, anaemia,cervico vaginal infections, heavy strenuous work during pregnancy contribute to the onset of preterm labour and still birth of premature and low birth weight babies.

Many of the stillbirths can be avoided by proper diet, adequate rest, regular antenatal check up.Early detection of high risk factors and their prompt management can save many antepartum deaths due to placental insufficiency. Modern gadgets like color Doppler, non stress tests can detect the fetal jeopardy before occurrence of stillbirth . Carefully performed obstetric ultrasonography can detect nuchal cord position and cord entanglement around body parts. Sonologist must alert the obstetrician of such occurrence, so that necessary care is taken during labour .Use of partograph and intrapartum fetal monitoring can detect fetal distress before major damage takes place. Avoidance of prolongation of labour ,especially the second stage ,careful selection of cases for instrumental deliveries and availability of neonatologist for resuscitation of asphyxiated newborn can reduce the rate of stillbirths.

\section{5 .CONCLUSION}

Large numbers of stillbirth are preventable by regular antenatal check up and institutional delivery. High rate of ante partum stillbirths due to hypertension, antepartum hemorrhage and preterm labour can be reduced by early recognition of the problem, color Doppler study to diagnose fetal growth restriction, and timely obstetric intervention .Ultrasonograpy to diagnose cord abnormalities, use of electronic fetal monitoring , partograph and prevention of prolongation of second stage of labour will help in reduction of intrapartum stillbirths. Improvement in female literacy ,health education to paramedical workers in identifying high risk pregnancies and their timely referral to tertiary care center and periodic departmental audits of all stillbirths can help in reduction of stillbirths 
IOSR Journal of Pharmacy

Vol. 2, Issue 3, May-June, 2012, pp.475-478

\section{REFERENCES}

1. Stanton C, Lawn JE, Rahman H, Wilczynska-Ketende K, Hill K: Stillbirth rates: delivering estimates in 190 countries. The Lancet 2006, 367:1487-1494

2. Di Mario S, Say L, Lincetto O: Risk factors for stillbirth in developing countries: a systematic review of the literature. Sex Transm Dis 2007, 34(7 Suppl):S11-21

3. Neonatal and Perinatal Mortality: Country, Regional and Global Estimates. [http://whqlibdoc.who.int/publications/2006/9241563206_eng.pdf] webcite

4. Cunningham G, Leveno K, Gilstrap L, Hauth J, Wenstrom K: Williams Obstetrics. 22nd edition. New York, NY: The McGraw-Hill Professional Publishing; 2005.

5. Lawn JE, Yakoob MY, Haws RA, Soomro T, Darmstadt GL, Bhutta ZA: 3.2 million stillbirths: epidemiology and overview of the evidence review. BMC Pregnancy and Childbirth 2009, 9 (Suppl 1):S2.

6. Goldenberg RL, McClure EM, Bann CM: The relationship of intrapartum and antepartum stillbirth rates to measures of obstetric care in developed and developing countries. Acta Obstet Gynecol Scand 2007, 86(11):1303-1309

7. $\quad$ Nayak AH, Dalal AR ,A review of stillbirth.J Obstet Gynecol India.1993;43:225-229

8. $\quad$ Korde-Nayak VN,Gaikwad PR,Causes of Stillbirth.J.Obstet Gynecol India2008;58(4):314-318

9. Kameshwaran C,Bhatia BD, Bhat BV et al, Perinatal mortality; A hospital based study.Indian Paediatrics.1993;30:997-1001

10. Githa $\mathrm{k}$,Yamuna,Gopal et al,Perinatal outcome in Pregnancy induced hypertension in a referral maternity hospital.J Obstet Gynecol India.1992;42:607-610

11. Ravikumar M,Devi A,Bhat V, et al.Analysis of stillbirths in a referral hospital.J Obstet Gynecol India.1996;46:791-796

12. Sujata,Das V,Agrawal A, A study of perinatal deaths at a tertiary care hospital. .J Obstet Gynecol India.2008;58(3):235-238

13. Chitra Kumari ,Kadam NN,Kshirsagar A,et al,Intrauterine fetal death;A prospective study. .J Obstet Gynecol India.2001;51:94-97

14. Uchil NA ,Nanavati MS, Purandare CB,et al. Stillbirths. .J Obstet Gynecol India 1990;40:361-3 